\title{
Desigualdade racial, Racismo e Seus efeitos
}

\section{Maria Helena Rodrigues Navas Zamora}

\section{Resumo}

$O$ artigo discute as noções de raça, racialismo e racismo para produzir uma reflexão sobre alguns dados concretos sobre a desigualdade racial no Brasil, mostrando que tal dimensão não pode ser reduzida somente à pobreza. Partindo do referencial da produção de subjetividade e da concepção de biopoder de Foucault, são examinados alguns estudos que tratam do racismo operando seus efeitos no acesso à saúde e educação. Este trabalho também visa empreender uma breve revisão da literatura sobre o tema nas pesquisas e estudos no campo da psicologia.

Palavras chave: raça; racismo; desigualdade racial; efeitos do racismo.

\section{RACIAL INEQUALITY, RACISM AND ITS EFFECTS}

\begin{abstract}
The article discusses the notions of race, racialism and racism in order to reflect upon some of the concrete date on the issue of social inequality in Brazil, showing that such dimension cannot be reduced to poverty. From the referential of the production of subjectivity and the concept of biopower in Foucault's works, some studies that analyze the issue of racism and how it operates concerning the acess to health and education will be examined. This work also intends to start a brief revision of the theme's literature on researches and studies on the field of psychology.
\end{abstract}

Keywords: race; racism; racial inequality; the effects of racism.

^ Doutorado (1999) em Psicologia Clínica pela PUC-Rio. Docente da graduação em Psicologia da PUC-Rio. Pontifícia Universidade Católica do Rio de Janeiro, Centro de Teologia e Ciências Humanas, Departamento de Psicologia. Rua Marquês de São Vicente, 225. Edifício Cardeal Leme. Sala 217. Gávea - Rio de Janeiro, RJ - Brasil.

E-mail: zamoramh@yahoo.com.br 
É uma simples verdade que nós todos precisamos apenas ouvir e ver: nenhum de nós é livre, se um de nós está preso (A Solomon Burke, in memoriam)

O presente artigo pretende produzir uma reflexão sobre alguns dados concretos sobre a desigualdade racial dos negros brasileiros - grupo da população em quem focalizamos. Entendemos que as diversas e complexas dimensões da desigualdade racial não podem ser reduzidas à desigualdade de classe, embora se articulem com ela.

Este trabalho também visa empreender uma breve revisão da literatura sobre o tema nas pesquisas e estudos no campo da psicologia e em outros campos do saber que estão em permanente diálogo com as práticas do psicólogo. Aqui pretendemos destacar alguns aspectos dos efeitos do racismo que consideramos mais relevantes - como as questões ligadas à saúde e educação.

Partindo do referencial da produção de subjetividade e da concepção de biopoder de Foucault, são examinados alguns estudos que tratam dos efeitos do racismo como vetor de subjetivação (GUATTARI, 1990; GUATTARI, 1992; GUATTARI; ROLNIK, 1996). Entendendo subjetividade como formas de viver que podem ser prescritas e proscritas; que podem ser tanto individuais quanto coletivas; homogêneas e aprisionadas; mas também podem ser singulares e experimentar novos territórios de existência. A subjetividade é algo modelado, produzido por processos coletivos, institucionais, sociais, que atravessam os indivíduos. Produzir subjetividades tem valor estratégico essencial para o capitalismo em sua forma atual, pois permite que ele se instaure, se legitime e se reproduza.

É no exame das dimensões abismais da desigualdade racial que é possível compreender a importância de tal discussão. Se a ideia de raça não faz sentido do ponto de vista da ciência, por outro lado ela pode ajudar a compreender o sentido de muitas ações que pressupõem sua existência (GUIMARÃES, 2002). "Não há raças; [o que] há é racismo", diz Joel Rufino dos Santos (SANTOS, 2009, p. 172). E é ainda o racismo que diz muito sobre como vão viver e morrer os negros no Brasil.

\section{ESTABELECENDO CONCEITOS: RAÇA, RACIALIZAÇÃO, RACISMO}

A noção de raça foi criticada como ideologia, depois de sua suposta existência justificar a colonização, escravização, segregação, esterilização, perseguição e morte de milhões de pessoas (NASCIMENTO, 1978; SANTOS, 2000; BLACK, 2004; SILVA Jr., 2008). Contudo, raça é um operador social que continua a produzir efeitos, sendo usada para agregar indivíduos e grupos que compartilham certos aspectos físicos observáveis e ajuda a determinar uma atitude negativa frente a eles. Raça é uma construção social essencialista, amplamente aceita (MUNANGA, 2010), criado e reforçado em práticas cotidianas (ESSED, 1991; SCHWARCZ, 1998). Se levada em conta como uma categoria analítica, raça/racismo é capaz de desvelar muitas formas de exercício de poder opressivo e de favorecer nosso entendimento da sociedade e da subjetividade que produz. 
É facilmente constatável que a maioria das pessoas ainda pensa em termos de racialização (ou racialismo), ou seja, acredita que há distintas raças humanas. Esta crença desenha verdadeiros mapas de navegação social para os brasileiros, desde sua primeira socialização. Contudo, o racialismo não implica necessariamente no racismo. O racismo consiste na idéia de que algumas raças são inferiores a outras, atribuindo desigualdades sociais, culturais, políticas, psicológicas, à "raça" e, portanto, legitimando as diferenças sociais a partir de supostas diferenças biológicas.

Parte importante deste jogo de dominação é, como adverte Walter Benjamin, transformar a história em uma história oficial dos vencedores, um registro das vitórias dos grupos dominantes. Contudo, o autor nos convoca a "escovar a História a contrapelo" (BENJAMIN, 1992, p. 161), ou seja, a construir uma história crítica, anti-hegemônica, rejeitando a possibilidade de silenciamento da memória:

Pensamos que não importa saber se quando algumas escravas "azedavam" a comida de suas senhoras, fugiam, ou, na pior das hipóteses, se matavam, ou empreendiam qualquer ação para tornar suas existências mais suportáveis, tinham a medida exata do que isso iria acarretar. Importa sim, ter em mente que agiam segundo o que, no limite, lhes era exigido para se manterem vivas. $\mathrm{O}$ que parece um ato de crueldade era, naquele instante, a saída para quem não é mero expectador da vida, mas nela está mergulhado e de alguma maneira intervém no seu curso. Foram os pequenos gestos, aparentemente sem importância para o conjunto da sociedade que aos poucos foram minando o edifício escravista, de sorte que chegou o momento que outra paisagem se configurou" (NASCIMENTO, 2005, p. 105).

No caso dos negros vencidos, o desafio é construir e recuperar a história da multiplicidade de sua resistência: desde o suicídio nos navios negreiros, das revoltas na senzala, das fugas para os quilombos, dos movimentos anti-racistas, da reação à repressão cultural e religiosa imposta pelos senhores até o enfrentamento das múltiplas práticas racistas, pulverizadas no cotidiano atual.

A partir da admissão de que pessoas com certos traços raciais (como a pele de cor escura) são inferiores (racismo) justifica-se sua posição desvantajosa na sociedade e seu assujeitamento. Guattari (1996) menciona mecanismos de segregação, infantilização e culpabilização que operam produzindo sentimentos de solidão, inferioridade, incapacidade, dependência e culpa sobre aqueles que tentam novas formas de se colocar no mundo. Isso é especialmente verdadeiro em relação aos negros e a outros grupos que apresentam características somáticas inferiorizadas ao longo da história. Espera-se que eles se mantenham em lugares sociais subalternizados, não resistam à dominação e que sejam gratos porque alguém lhes tira desse lugar (RAMÃO, MENEGHEL; OLIVEIRA, 2005).

Mostrando os mecanismos racistas que parecem mais suaves, "psicológicos", não pretendo esquecer que a discriminação direta, a violência e o extermínio não só são possíveis, como são muito empregados. Trata-se de mostrar que uma 
coisa prepara, justifica e banaliza a outra. Baptista (1999) chama de 'genocídio' não apenas aos assassinatos concretos, mas também aos assassinatos subjetivos: os discursos "neutros", enunciados por especialistas e outros "autorizados a falar", que condenam a expressão singular; que fragilizam, patologizam, "fragmentam a violência da cotidianidade, remetendo-a a particularidades individuais" (BAPTISTA, 1999, p.46). Um assassinato afia a arma do outro. A ação do racismo "enfraquece a vítima" (BAPTISTA, 1999, p.46) e faz com que ela internalize sua falha e sua culpa em não ser aquilo que é desejável (VERGNE, 2010); tornando-a mais vulnerável, menos propensa a se defender e a afirmar sua diferença.

Não podemos esquecer que muitas formas de se pensar os negros são provenientes do discurso científico do século XIX, produzido a partir das teorias raciais europeias. O racismo "explicado" pela ciência foi a forma de manter a desigualdade de tratamento entre brancos e negros, naquele momento histórico (NUNES, 2006). Tanto quanto as mulheres, as crianças e outros grupos não brancos, os negros são historicamente vistos pelo poder e pelo senso comum como menos inteligentes e racionais (portanto menos capazes para o trabalho intelectual) e mais ligados ao universo dos instintos, das emoções, mais propensos às superstições (CORRÊA, 2006). Como alerta Vilhena (2006), "o branco foi e continua sendo a manifestação do Espírito, da Ideia e da Razão. O branco e a brancura são os únicos legítimos herdeiros e construtores do progresso e desenvolvimento do homem. Eles são a cultura e a civilização, em uma palavra - a "humanidade"".

Deleuze e Guattari (2004) trabalham com a ideia de que o racismo europeu não opera com a categoria do negro (ou de outros grupos) como sendo o "outro" da civilização. Não há outro, nem pode haver. O que há são os desvios e variações determinados a partir "do rosto do 'Homem-branco-médio-qualquer' [...]: assim temos o homem amarelo, o homem negro, como homens de segunda ou terceira categoria" (FIGUEIREDO, 2009). O racismo, para os autores, opera confinando os desvios em determinados territórios, mas na verdade "[...] jamais suporta a alteridade (é um judeu, é um árabe, é um negro, é um louco... etc.). Do ponto de vista do racismo, não existe exterior, não existem as pessoas de fora. Só existem pessoas que deveriam ser como nós, e cujo crime é não o serem" (DELEUZE; GUATTARI, 2004, p. 45).

\section{RACISMO À BRASILEIRA: FENÔMENO TÃo PRESENTE QUANTO NEGADO}

Vários estudos mostram o paradoxo de um racismo brasileiro que se destaca pela inexistência de racistas. Um traço recorrente em várias pesquisas aqui analisadas é que, nas entrevistas, as pessoas relatam que o preconceito racial na sociedade existe, mas não o admitem em si mesmos (SILVA, 1998; SCHWARCZ, 2001; FIGUEIREDO; GOSFROGUEL, 2009; CAMINO et. al., 2001; FERREIRA, 2002).

Negado patologicamente, as propostas para a redução de tal iniquidade encontram muitas resistências, sustentando a ideia de que não é preciso fazer nada, pois afinal somos um povo mestiçado e de natureza cordial (CARNEIRO, 2003). $\mathrm{O}$ mito de que vivemos uma democracia racial, já bastante denunciado, encontra 
persistências muito concretas no Brasil de hoje; procurando desqualificar como um potencial racismo às avessas as iniciativa de equilibrar as notáveis inequidades sociais, de que trataremos mais adiante.

A "raça" ainda hoje segue originando percepções de como seriam as características morais dos negros. Giacomini (2008), na revisão dos mais importantes estudos nacionais sobre o assunto, menciona que neles os negros aparecem como sendo "brigões"; indolentes; pouco higiênicos. Mesmo hoje, certa identidade é atribuída aos negros; eles seriam instáveis e perigosos (SANTOS, 2000). Outros estereótipos ainda persistem; como mostra Silva Bento (2002), acentuando que diferentes estudiosos têm se preocupado com a maneira como os negros são atingidos pela ideologia do branqueamento e também que a militância negra tem destacado persistentemente que as dificuldades de identificação racial estão ligadas à baixa auto-estima e tornam mais árdua a luta deste segmento contra a discriminação racial. A autora aponta tanto para a negação do racismo subjacente a tais práticas de violência, como para o difícil movimento de destacar-se como negro, de estar "fora de lugar", mas não poder reagir a uma opressão não assumida.

Como explica Neuza Santos Souza, no importante livro Tornar-se Negro (1983), a violência racista atinge o corpo do negro não necessariamente de forma física. O corpo do negro é visto pejorativamente em relação ao do branco; ressaltando-se principalmente os atributos ligados à força física (ligada à capacidade para o trabalho manual) e a uma hipersexualidade, quase descontrolada (PINAR, 2008). Souza lembra que "é a autoridade da estética branca quem define o belo e sua contraparte, o feio, nesta nossa sociedade classista onde os lugares de poder e tomada de decisões são ocupados hegemonicamente por brancos. [...] 'O negro é o outro do belo"' (SOUZA, 1983, p. 29, grifos da autora).

Os atributos físicos ditos dos negros são geralmente pensados no negativo e sempre postos em comparação desfavorável aos ideais estéticos etnocêntricos. Dois exemplos disso são a visão do cabelo crespo como sendo "ruim", "duro", "bombril" (palha de aço) e do cabelo liso, que seria "bom"; bem como a apreciação depreciativa do nariz dos tipos negros, que seria "chato", "grosso" em oposição ao "fino" dos brancos, que seria considerado bonito (GOMES, 2003; VILHENA, 2006) e mais que isso, o ideal da beleza.

O corpo, pensado com atributos pejorativos, deixa de ser vivido como uma fonte de alegria e prazer. Por meio da aceitação do racismo - até mesmo por falta de outros modelos positivos para se constituir e se identificar - se estabelece uma relação persecutória entre o negro e o seu corpo (COSTA, 1984). A relação com o próprio corpo então passa a ser de vigilância, no sentido de mascarar as características "diferentes" do modelo dominante e portanto indesejáveis. Instala-se a preocupação em disfarçar seus traços físicos originais e de fazer-se "passar por branco". Mas ao desejar embranquecer, o negro não se permite existir; ele instaura o projeto de sua própria extinção.

Insisto na violência destas formas ditas douces de dominação e endosso os estudos mencionados que mostram que elas não podem ser entendidas separadas, do ataque corporal, como fenômenos inteiramente diferentes. Tornar difícil 
alguém ser aquilo que é; fazer com que a pessoa seja vista no negativo e pensada em sua suposta "falta"; fazer com que a própria pessoa se veja no negativo e que conspire contra seu crescimento - tudo isso é violento, é brutal. Desde cedo, na mídia e na escola, senão na própria família, a criança negra vê e sente a desvalorização de seu corpo e a fundamentação de padrões estéticos que desprezam o seu tipo, reservando a idéia de beleza para o tipo branco, quando não o nórdico. Tornar-se negro, portanto, é vencer inúmeros obstáculos, onde o referencial é sempre o mundo branco; é um desafio doloroso.

Esta desqualificação da negritude não pode ser desvinculada da história da escravidão, nem do fato do Brasil ter resistido tanto a aboli-la oficialmente (NUNES, 2006; FLAUZINA, 2008). Não se pode separar a ideia de que os negros são potenciais criminosos do temor de sua revolta, desde o regime escravo até os discursos contemporâneos, clamando por maior controle social, por mais repressão penal. Hoje este pedido de contenção das "classes perigosas" se naturaliza como uma "guerra civil", onde negros pobres são os inimigos internos a serem caçados e combatidos (COIMBRA, 2001). Hoje uma certa visão de "segurança pública" procura instituir uma repressão explícita como biopolítica, que não pode - e talvez nem pretenda - ocultar seu racismo subjacente (BATISTA, 2003; NASCIMENTO, 2008; NUNES, 2010; RAMOS, 2011).

A liberdade não garantiu condições dignas de vida e a lógica da exploração escravagista encontrou muitas formas de continuidade: "não há o que discutir sobre nossa forma de lidar tanto com a escravidão como com o racismo: suavizamos a primeira e negamos o segundo" (FLAUZINA, 2008, p. 47).

\section{O RACISMO E SEUS EFEITOS: ACESSO À SAÚdE E EDUCAÇÃo}

A população brasileira, de acordo com levantamento do IBGE de 2010, tem $42,1 \%$ de pardos e $5,9 \%$ de negros autodescritos. Reunindo os dois conjuntos, temos quase metade da população total. Os resultados do Censo 2010, que à época da escrita desse artigo apenas começavam a circular, mostram o Brasil como uma das maiores nações negras do mundo e que, pela primeira vez, a maior parte da população se autodeclara negra. Estes dados evidenciam o quanto o termo "minoria" é inadequado.

Se os negros são a maioria do país, supostamente deveriam ter a mesma equivalência em termos de acesso a direitos sociais. Contudo, a "parte negra" concentra dados iníquos em relação à branca, formando, na prática, dois países. A desigualdade social tem cor. Ela deriva, principalmente, "da forte concentração de renda no segmento mais rico da sociedade [...]. Os negros frequentam a riqueza do país, mas são participantes minoritários. Os brancos são mais ricos e mais desiguais. Os negros, mais iguais e mais pobres" (HENRIQUES, 2001, p. 49).

Se tomarmos qualquer dado que informe sobre o desenvolvimento humano e a qualidade de vida - educação, saúde, moradia, emprego, renda, expectativa de vida, acesso a equipamentos sociais - veremos que os negros estão em grande e injusta desvantagem. Parece importante definir que " [...] as desigual- 
dades sociais são ditas raciais quando se encontrem e se comprovem mecanismos causais operando ao nível individual e social que possam ser retraçados ou reduzidos à idéia de raça" (GUIMARÃES, 1999, s/p.).

A violência estrutural fica bem demonstrada em dados como o "Racismo, Pobreza e Violência" (PNUD, 2005). Ali veremos que, apesar do crescimento da renda das últimas décadas, o percentual de negros pobres nunca ficou abaixo de $64 \%$. Embora sejam mais de $45 \%$ da população total, os negros são $70 \%$ entre os $10 \%$ mais pobres e não passam de $16 \%$ entre os $10 \%$ mais ricos.

Para darmos alguns exemplos ilustrativos das diferenças nesses "dois países", sabemos que a expectativa de vida, segundo o IDH (Índice de Desenvolvimento Humano), se desagregado por gênero e raça, é, respectivamente: homens brancos, 69 anos; mulheres brancas, 71 anos; já entre homens negros é de 62 anos; e entre mulheres negras, de 66 anos. Os dados relativos à renda informam que o PIB per capita das mulheres negras é de 0,76 salários mínimos (SM); os dos homens negros: 1,36 SM; mulheres brancas: 1,88 SM; e homens brancos, 4,74 SM (OLIVEIRA, 2003).

Deste grande grupo afrodescendente, aproximadamente a metade é composta de mulheres, o que representa cerca de $24 \%$ do total da população brasileira. Sobre elas incide uma tríplice discriminação: de raça, de gênero e de classe social. Elas constituem a parcela mais pobre, são as que possuem a situação de trabalho mais precária, que têm os menores rendimentos e as mais altas taxas de desemprego (DIEESE, 2003). As mulheres encontram-se mais concentradas, proporcionalmente, em trabalhos informais e mais precários e mal remunerado do que os homens, como é o caso do trabalho doméstico. Ou seja: "Num quadro global de gravíssimas desigualdades sociais, já amplamente reconhecido, evidencia-se uma nítida hierarquia que tem, no topo, os homens brancos (não negros) e que vai descendo para as mulheres brancas, homens negros (e pardos) e mulheres negras" (QUADROS, 2004).

É indisfarçável que "há 53 milhões de pobres e, desses, 22 milhões são indigentes. $65 \%$ e $70 \%$, respectivamente, desses pobres e indigentes são pessoas negras" (CARNEIRO, 2003, p.1). Podemos portanto dizer que no Brasil, mesmo com variações regionais, a pobreza e a miséria são predominantemente negras.

É preciso superar o pensamento que prefere admitir que melhorando nossa injustiça social, a questão racial será resolvida, já que o que há é apenas preconceito de classe. $\mathrm{O}$ racismo não é redutível à pobreza e miséria. Isto vem sendo desmentido desde os anos 50 (GIACOMINI, 2008) e confirmado em estudos mais recentes (FIGUEIREDO, 2004).

Na área da educação há notáveis diferenças no acesso à escola entre brancos e negros. As diferenças raciais, contudo, são muito marcantes: os negros e negras estão menos presentes nas escolas, apresentam médias de anos de estudo inferiores e taxas de analfabetismo bastante superiores. As desigualdades se ampliam quanto maior o nível de ensino. $\mathrm{O}$ acesso ao ensino médio, ainda bastante restrito em nosso país, é significativamente mais limitado para a população ne- 
gra, que, por se encontrar nos estratos de menor renda, é mais cedo pressionada a abandonar os estudos e ingressar no mercado de trabalho. (IPEA, 2008). Em $2009,4,7 \%$ dos pretos e 5,3\% dos pardos nesta faixa etária tinha diploma de ensino superior, contra $15 \%$ dos brancos e $62,6 \%$ dos estudantes brancos entre 18 e 24 anos estavam na universidade, contra $28,2 \%$ dos negros e $31,8 \%$ dos pardos (IBGE, 2010), o que impacta especialmente a vida dos jovens. Como foi mostrado, há muita diferença no tratamento dado aos dois grupos. Esse dado aponta para a formação dos professores, pois "de nada adianta dispor de livro didático e currículo apropriados se o professor for preconceituoso, racista, e não souber lidar adequadamente com a questão" (VALENTE, 2005, s/p.).

Sendo persistentes, as formas preconceituosas de ver reduzem as oportunidades dos negros em vários campos da garantia de direitos e cidadania. Pesquisas recentes mostram que as expectativas dos educadores em relação às crianças e jovens negros e também estreitam suas oportunidades quando crescem. Santos sustenta que muitas escolas "partem da crença de que alunos pobres e negros não são educáveis" (VALENTE, 2005, p. 44). Com raras exceções, o combate ao racismo não é uma meta nas instituições escolares; não é parte da formação dos professores; não é discutido nem mesmo nas famílias dos alunos negros, talvez porque tenham sofrido os pais tenham sofrido os mesmos ataques e tenham se resignado, propagando este conformismo (MIRANDA, 2004).

No exame do conteúdo dos livros escolares e literatura infanto-juvenil os negros não raro são retratados como fracos, feios, maus, estúpidos ou mesmo são grotescos (LIMA, 2005) e também pode ocorrer a omissão de aspectos importantes de sua história de resistência (LUCINDO, 2010). Muitas vezes eles são personagens tristes, vitimizados e degradados, presos ao que Batista (2003) chamou, em outros contextos, de estética da escravidão.

Ou seja, pode-se dizer que na escola as tensões raciais são apagadas "magicamente", basta não falar delas. Mas os efeitos se impõem, tornando o ambiente escolar hostil e facilitando os processos de suposta desistência de continuar a estudar:

Não precisamos ser profetas para compreender que o preconceito incutido na cabeça do professor e sua incapacidade de lidar profissionalmente com a diversidade, somando-se ao conteúdo preconceituoso dos livros e materiais didáticos e às relações preconceituosas entre alunos de diferentes ascendências étnico-raciais, sociais e outras, desestimulam o aluno negro e prejudicam seu aprendizado. O que explica o coeficiente de repetência e evasão escolar altamente elevado do alunado negro, comparativamente ao do alunado branco. (MUNANGA, 2005, p. 16).

Na saúde, os dados epidemiológicos são eloquentes, mostrando a diminuição da qualidade de vida e da expectativa de vida da população negra. Em geral, este segmento apresenta níveis mais baixos de instrução, reside em áreas com menos serviços de infra-estrutura básica, tem menos acesso ao Sistema Único de Saúde e, quando dispõe dele, depara-se com menor qualidade. Ou seja, essa parte 
da população brasileira vivencia, em quase todas as dimensões de sua existência, situações de exclusão, marginalidade e/ou discriminação sócio econômica, o que a coloca mais vulnerável aos agravos à saúde e a faz adoecer de doenças curáveis e morrer antes do tempo, de mortes evitáveis (CHAGAS, 2010; CUNHA, 2001). Contudo, o racismo estrutural e institucional tem sido discutido e enfrentado na área da saúde, com a implementação de ações concretas, enfatizando a formação dos trabalhadores (BARBOSA, 2006).

Mas o negro, em especial o homem, não escapa de outra seletividade perversa. O Programa para o Desenvolvimento das Nações Unidas (PNUD, 2005) mostra que cerca de 30 mil brasileiros são assassinados por ano. A maioria dessas mortes violentas é pobre, negra e tem entre 15 e 24 anos. Muitos moram nos territórios estigmatizados das grandes cidades, as favelas ou são tão pobres que não têm onde morar. Há muitos relatos concretos de execuções sumárias contra rapazes e mesmo meninos, sem registro criminal e sem oportunidade de defesa (JAHANGIR, 2003).

Também são eloquentes os dados do "Mapa da Violência 2006", com dados de até 2004, organizado por Julio Waiselfisz (2006), que mostrou que os homicídios vitimam preferencialmente os homens (93\%); mas vitimam muito mais os negros, cujas mortes chegam a ser mais de cinco vezes superior ao dos brancos. Os dados dessas mortes evitáveis apontam para uma continuidade de práticas históricas repressivas e genocidas contra essa população (ZAMORA; CANARIM, 2009). O Mapa de 2012 (dados de 2011) mostra o reforço desta tendência, com a quantidade de vítimas brancas caindo e o de negros aumentando. Para cada dois brancos assassinados em 2002, morreram aproximadamente três negros. Já em 2010, para cada dois brancos assassinados 4,6 negros foram vítimas de homicídio.

\section{Conclusões}

A luta para terminar com grandes iniquidades contra parte do nosso povo, herança da escravidão e do colonialismo, deveria envolver todos. As políticas públicas deveriam ser urgentes e ter como objetivo precípuo a participação da população negra no processo de desenvolvimento coletivo, a partir de sua história e cultura, visando a eliminação das desigualdades. Estas são iniciativas que cabem a toda sociedade, em um processo educativo, em um sentido mais amplo.

O tema do racismo é considerado por vários autores como sendo tão importante quanto pouco abordado pela psicologia (MIRANDA, 2004; NASCIMENTO, 2005; NUNES, 2006; OLIVEIRA, MENEGHEL; BERNARDES, 2009; CHAGAS, 2010). De fato, na pesquisa empreendida para este artigo, havia mais que o triplo de publicações nas áreas de saúde, educação, sociologia, sociologia, consideradas individualmente, que na psicologia. O que coloca questões a pensar sobre formação e compromisso social (NÓRTE, MACIEIRA; FURTADO, 2010). Porém, é notável que o assunto ganha cada vez mais atenção na psicologia, merecendo um número crescente de estudos. 
O racismo constitui nossa história, estrutura as relações em nossa sociedade e precisa ser encarado como o grave problema que realmente é (VIEIRA, 1995; SANTOS, 2009). Ele opera talvez a mais poderosa clivagem na nossa sociedade, pois justifica inclusive o poder de deixar morrer ou de matar do Estado (FOUCAULT, 2005; AGAMBEM, 2007; ALVARENGA FILHO, 2010). Ele opera e ajuda a operar uma seletividade entre quem tem ou não tem o direito a uma vida cidadã; entre quem deve ser preservado e protegido e quem é a vida indigna, que não merece ser vivida.

\section{REFERÊNCIAS}

ALVARENGA FILHO, J. R. A "Chacina do PAN" e a produção de vidas descartáveis na cidade do Rio de Janeiro: "Não dá pé não tem pé nem cabeça não tem ninguém que mereça não tem coração que esqueça". 2010. Dissertação (Mestrado) - Universidade Federal Fluminense, Niterói, 2010.

AGAMBEM, G. Homo Sacer. O poder soberano e a vida nua I. Belo Horizonte: UFMG, 2007.

BAPTISTA, L. A. S. A cidade dos sábios: reflexões sobre a dinâmica social nas grandes cidades. São Paulo: Summus, 1999.

BARBOSA, M. I. S. Racismo: doença na saúde. Brasília: UNIFEM, 2006. Disponível em: <http://www.unifem.org.br/sites/1000/1070/00001665.pdf>. Acesso em: 03 maio 2010.

BATISTA, V. M. O medo na cidade do Rio de Janeiro: dois tempos de uma história. Rio de Janeiro: Revan, 2003.

BENJAMIN, W. Teses sobre a Filosofia da História. Lisboa: Relógio D.Água, 1992.

BLACK, E. A guerra contra os fracos. São Paulo: A Girafa, 2004.

CAMINO, L.; SILVA, P.; MACHADO, A.; PEREIRA, C. A face oculta do racismo no Brasil: uma analise psicossociológica. Revista Psicologia Política, v. 1, n. 1, p. 13-36, 2001.

CHAGAS, A. M. Comunidade Popular, População Negra, Clínica e Política: um outro olhar. 2010. Dissertação (Mestrado) - Universidade Federal Fluminense, Niterói, 2010.

CARNEIRO, S. Ideologia tortuosa. Revista Caros Amigos. Ano III, no. 35, fevereiro de 2000. Disponível em: <http://www.sinprosp.org.br/reportagens entrevistas. asp? especial=16\&materia $=71>$. Acesso em: 07 jul. 2009. 
COIMBRA, C. Operação Rio: o mito das classes perigosas: um estudo sobre a violência urbana, a mídia impressa e os discursos de segurança pública. Niterói, Oficina do Autor, 2001.

CORRÊA, L. G. Corpo exposto: a representação do negro em dois anúncios de telefonia celular. UNIrevista. Rio Grande do Sul, v. 1, n. 3, jul. 2006. Disponível em: <http://www.alaic.net/ponencias/UNIrev_Correa.pdf>. Acesso em: 09 maio 2010 .

COSTA, J. F. Da cor ao corpo: a violência do racismo. In: . Violência e Psicanálise, Rio de Janeiro: Graal, 1984.

CUNHA, E. M. P. Mortalidade infantil e raça: as diferenças da desigualdade. Jornal da Rede Saúde, São Paulo, n. 23, p. 48-50, 2001.

DELEUZE, G.; GUATTARI, F. Rostidade. In: Mil Platôs. capitalismo e esquizofrenia. v. 3, p. 31-61. São Paulo: 2004.

DIEESE - Departamento Intersindical de Estatíticas e Estudos Sócio-Econômicos. Mulher Negra: dupla discriminação nos mercados de trabalho metropolitanos, 2003. Disponível em: <www.dieese.org.br/esp/negro2003.pdf>. Acesso em 07 jul. 2009.

ESSED, P. Understanding everyday racism: an interdisciplinary theory. California: Sage Publications, 1991.

FERREIRA, R. F. O brasileiro, o racismo silencioso e a emancipação do afrodescendente. Revista Psicologia e Sociedade. v. 14, p.69-86. Porto Alegre, jun. 2002.

FIGUEIREDO, A.; GROSFOGUEL, R. Racismo à brasileira ou racismo sem racistas: colonialidade do poder e a negação do racismo no espaço universitário. Revista Sociedade e Cultura. Goiânia, v. 12, n. 2, 2009. Disponível em: <http:// www.revistas.ufg.br/index.php/fchf/article/view/9096>. Acesso em: $09 \mathrm{dez}$. 2010.

FIGUEIREDO, L. Deleuze, migrações e racismo. Revista Polêmica. Caderno Imagens. Rio de Janeiro, n. 4, out./dez. 2009. Disponível em: <http://www. polemica.uerj.br/8(4)/cimagem/p8(4)_3.htm>. Acesso em: 19 nov. 2010.

FLAUZINA, A. L. P. Corpo negro caído no chão: o sistema penal e o projeto genocida do Estado brasileiro. Rio de Janeiro: Contraponto, 2008.

FOUCAULT, M. Em defesa da sociedade. São Paulo: Martins Fontes, 2005. 
GIACOMINI, S. M. Estereótipos e preconceito racial no Brasil. In: PAIVA, A. R. (Org.). Noticias e reflexões sobre discriminação racial. Rio de Janeiro, PUC-Rio, 2008.

GOMES, N. L. Trajetórias escolares, corpo negro e cabelo crespo: reprodução de estereótipos ou ressignificação cultural?. Revista Brasileira de Educação, Belo Horizonte, n. 21, p. 40-51, 2002.

GUATTARI, F. As Três Ecologias. Campinas: Papirus, 1990.

GUATTARI, F. Caosmose: um novo paradigma estético. São Paulo: 34, 1992.

GUATTARI, F.; ROLNIK, S. Micropolítica: cartografias do desejo. Petrópolis: Vozes, 1996.

GUIMARÃES, A. S. A. Racismo e anti-racismo no Brasil. São Paulo: 34, 1999.

HENRIQUES, R. Desigualdade racial no Brasil: evolução das condições de vida na década de 90. texto para discussão n. 807. IPEA, 2001, Disponível em $<$ http:// www.ipea.gov.br/pub/td/2001/td_0807.pdf>. Acesso em: 07 ago. 2010.

IBGE - Instituto Brasileiro de Geografia e Estatística. Sintese de Indicadores Sociais. Brasília, 2010.

IPEA - Instituto de Pesquisa Econômica Aplicada. Retrato das Desigualdades de Gênero e Raça - Análise preliminar dos dados. Brasília, 2008.

JAHANGIR, A. Civil and Political Rights, Including The Question of Desappearances and Summary Executions. Extrajudicial, Summary or Arbitrary Executions. mission to brazil/commission of human rights: Nações Unidas, 2003.

LIMA, H. P. Personagens negros: um breve perfil na literatura infanto-juvenil. In: MUNANGA, K. (org.). Superando o racismo na escola. Brasília: Ministério da Educação, 2005, p. 101-115.

LUCINDO, W. R. S. Desvitimizar para humanizar: uma análise sobre a escravidão nos livros didáticos. Revista Antiteses, Universidade Estadual de Londrina, v. 3, n. 6, jul./dez. 2010.

MIRANDA, M. A. A beleza negra na subjetividade das meninas. Um caminho para as Mariazinhas. Considerações psicanalíticas. 2004. Dissertação (Mestrado) - Universidade do Estado de São Paulo, São Paulo, 2004.

MUNANGA, K. Superando o racismo na escola. Brasília: MEC-SECAD, 2005. 
MUNANGA, K. Educação e Cotas. In: Audiência Pública do Supremo Tribunal Federal, Brasília, 2010.

NASCIMENTO, A. O Genocídio do Negro Brasileiro. Rio de Janeiro: Paz e Terra, 1978.

NASCIMENTO, M. C. Considerações sobre o Racismo e Subjetividade: Problematizando Práticas. Desnaturalizando Sujeitos e Lugares. 2005. 112 f. Dissertação (Mestrado). Universidade Federal Fluninense, Niterói, 2005.

NASCIMENTO, A. R. De Auschwitz a Tropa de Elite: modulações do estado de exceção? Revista Mnemosine, Rio de Janeiro, v. 4, n. 2, p. 115-150, 2008. Disponível em: <http://www.mnemosine.com.br/mnemo/index.php/mnemo/ article/view/318/527>. Acesso em: 22 set. 2012.

NÓRTE, C. E.; MACIEIRA, R. M.; FURTADO, A. L. L. (Orgs.) Formação: ética, política e subjetividades na Psicologia. Rio de Janeiro: Conselho Federal de Psicologia, 2010.

NUNES, S. S. Racismo no Brasil: tentativas de disfarce de uma violência explícita. Revista de Psicologia da USP, São Paulo, v. 17, n. 1, 2006. Disponível em: $<$ http://www.revistasusp.sibi.usp.br/scielo.php?script=sci_arttext\&pid=S1678$51772006000100007 \& \operatorname{lng}=$ pt\&nrm=iso $>$. Acesso em: 09 ago. 2010.

NUNES, A. C. C. Cartografia do desassossego: um olhar clínico-político para o encontro entre os psicólogos e o campo jurídico. 2010. Dissertação (Mestrado) Universidade Federal Fluminense, Niterói, 2010.

OLIVEIRA, F. Saúde da população negra: Brasil ano 2001. Brasília: Organização Pan-Americana da Saúde, 2003.

OLIVEIRA, M. L. P.; MENEGHEL, S. N.; BERNARDES, J. S. Modos de subjetivação de mulheres negras: efeitos da discriminação racial. Revista Psicologia e Sociedade. Porto Alegre, v. 21, n. 2, p. 266-274, mai./ago., 2009. Disponível em: $<$ http://www.scielo.br/scielo.php? script=sci_arttext\&pid=S010271822009000200014\&lng=en\&nrm=iso>. Acesso em: 05 dez. 2011.

PINAR, W. F. O corpo do pai e a raça do filho: Noé, Schreber e a maldição do pacto. Revista Brasileira de Educação. Rio de Janeiro, v. 13, n. 37, p. 3535, jan./abr., 2008. Disponível em: <http://www.scielo.br/scielo.php?script=sci arttext\&pid $=\mathrm{S} 1413-24782008000100004 \& \operatorname{lng}=\mathrm{en} \& n r m=i s o>$. Acesso em $1 \overline{0}$ out. 2010. 
PNUD. Relatório de Desenvolvimento Humano Brasil 2005 - Racismo, pobreza e violência. Disponível em: <http://www.pnud.org.br/HDR/RelatoriosDesenvolvimento-Humano-Brasil.aspx?indiceAccordion=2\&li=li_RDHBrasil>. Acesso em: 02 jun. 2010.

QUADROS, W. Gênero e raça na desigualdade social brasileira recente. Estudos Avançados. São Paulo, v. 18, n. 50, abr. 2004. Disponível em: <http://www.scielo. br/scielo.php?script=sci_arttext\&pid=S0103-40142004000100010\&lng=en\&nr $\mathrm{m}=\mathrm{iso}>$. Acesso em: 10 out. 2010.

RAMÃO, S. R.; MENEGHEL, S. N.; OLIVEIRA, C. Nos caminhos de Iansã: cartografando a subjetividade de mulheres em situação de violência de gênero. Psicologia e Sociedade - ABRAPSO. Porto Alegre, v. 17, n. 2, jul./ dez. 2005. Disponível em: <http://www.scielo.br/scielo.php?pid=S010271822005000200011\&script=sci_arttext>. Acesso em: 09 out. 2010.

RAMOS, T. F. Vim buscar a sua alma. governamentalidade da política caveirão. 2011. Dissertação (Mestrado) - Universidade Federal Fluminense, Niterói, 2011.

SCHWARCZ, L. M. Sob o signo da diferença: a construção de modelos raciais no contexto brasileiro. Niterói: EDUFF, 1998.

SCHWARCZ, L. M. Racismo no Brasil. São Paulo: Publifolha, 2001.

SANTOS, J. R. O que é racismo? São Paulo: Brasiliense, 2000.

SANTOS, J. R. Mídia e produções de subjetividade: questões do racismo. In: Conselho Federal de Psicologia. Mídia e psicologia: produção de subjetividade e coletividade. Brasília: Conselho Federal de Psicologia, cap. 5, p. 157-174, 2009.

SILVA BENTO, M. A. Branqueamento e Branquitude no Brasil. In: CARONE, I; SILVA BENTO, M. A. (Org.). Psicologia social do racismo - estudos sobre branquitude e branqueamento no Brasil. Petrópolis: Vozes, 2002, p. 25-58.

SILVA, J. Violência e racismo no Rio de Janeiro. Niterói: EDUFF, 1998.

SILVA Jr., J. C. Não queríamos ser racistas: uma reação aos que insistem em dizer que não somos uma nação com problemas de cor. Afroamazonas, Manaus, 2008. Disponível em: <http://amazonida.orgfree.com/movimentoafro/nao_queriamos ser_racistas.PDF>. Acesso em: 08 out. 2010.

SOUZA, N. S. Tornar-se negro ou as vicissitudes da identidade do negro brasileiro em ascensão social. Rio de Janeiro: Graal, 1983. 
VALENTE, A. L. Ação afirmativa, relações raciais e educação básica. Revista Brasileira de Educação. Rio de Janeiro, n. 28, p. 62-77, jan./abr. 2005. Disponível em: $<$ http://www.scielo.br/scielo.php?script=sci_arttext\&pid=S141324782005000100006\&lng=en\&nrm=iso >. Acesso em: 13 out. 2010.

VERGNE, C. O Olhar da Medusa e a petrificação do outro: uma reflexão sobre as favelas cariocas. Revista Polêmica, Rio de Janeiro, v. 9, n. 3, p. 8-21, jul./ set. 2010. Disponível em: <http://www.polemica.uerj.br/ojs/index.php/polemica/ article/viewFile/39/75>. Acesso em: 11 out. 2010.

VIEIRA, B. Black resistence in Brazil: a matter of necessity. In: BOWNSER, B. P. Racism and anti-racism in world perspective. California: Sage Publications, 1995, p. 227-240.

VILHENA, J. A Violência da Cor: sobre racismo, alteridade e intolerância. Revista de Psicologia Política, Belo Horizonte, v. 6, n. 12, 2006. Disponível em: $<$ http://www.fafich.ufmg.br/ psicopol/seer/ojs/viewarticle.php?id=7>. Acesso em: 14 out. 2010.

WAISELFISZ, J. Mapa da Violência 2006: os jovens do Brasil. Brasília: OIE, 2006. Disponível em: <http://www.comunidadesegura.org/files/active/0/ mapaviolencia.pdf>. Acesso em: 07 maio 2010.

ZAMORA, M. H. e CANARIM, C. F. Direitos humanos de crianças e adolescentes: extermínio, racismo e o velho silêncio. In: SYDOW, E.; MENDONÇA, M. L. Direitos humanos no Brasil 2009. Relatório da Rede Social de Justiça e Direitos Humanos. São Paulo: Rede Social de Justiça e Direitos Humanos, 2009. p. 161-170.

Recebido em: 17 de fevereiro de 2011 Aceito em: 12 de junho de 2012 
